\title{
EDITORIAL
}

\section{Women in cardiology: the US experience}

\section{N K Wenger}

Heart 2005;91:277-279. doi: 10.1136/hrt.2004.047860

"You are not required to complete the work, but neither are you at liberty to abstain from it..." - Rabbi Tarfon, Pirke Avot 2:16

Correspondence to: Professor Nanette K Wenger, Division of Cardiology, Emory University School of Medicine, Atlanta GA 30322, USA; nwenger@ emory.edu
$\mathrm{T}$ his issue of Heart explores "Women in UK cardiology", ${ }^{\prime}$ displaying their underrepresentation in cardiology training programmes, their paucity of mentors, and their absence in leadership roles within the British Cardiac Society (BCS). We congratulate our British colleagues for their participation in this odyssey, designed to develop strategies to improve the recruitment and retention of female cardiologists. The BCS working group concluded that if a substantial portion of the undergraduate talent pool (the women) was lost to other specialties in the UK, it would prove increasingly difficult to maintain high standards of cardiology clinical practice, teaching, and research.

Please remember that the first mentor was a woman. In Homer's tale in ancient Ithaca, the goddess Athena descended to earth from Mount Olympus to guide the young Telemachus, son of Odysseus. Given the culture and customs of the times, she assumed the male guise of his tutor, Mentor.

What has transpired on the western side of the Atlantic? Can initiatives of the cardiology community in former British colonies provide guidance? Can our shared ventures enhance the participation worldwide of women in cardiovascular medicine?

Although women represent almost half of all new physicians trained annually in the USA, the challenge remains to increase the attraction of cardiology as a career choice for women. Examination of our successes to date and the activities planned can provide a foundation for continued accomplishment.

During the past 30 years, the percentage of US female physicians increased from $8 \%$ to $25 \%$. Concomitantly, women graduates of US medical schools increased from $8 \%$ to $44 \%$. In $2001,60 \%$ of all women physicians were younger than 45 years of age and a quarter were younger than age 35 . In the same year, almost $40 \%$ of all residents were women and $39 \%$ of them were in internal medicine residency programmes ${ }^{2}$ (a fifth of all women residents).

By contrast, 2000 data from the Association of American Medical Colleges for women in academia showed that $11 \%$ were professors, 19\% associate professors, $50 \%$ assistant professors, $18 \%$ instructors and $2.4 \%$ at other ranks. Only

\section{WOMEN IN US MEDICINE}

nine women were deans, 54 were senior associate deans, 233 were associate deans and 208 were assistant deans. ${ }^{3}$ This constitutes prominent under-representation of women in leadership roles in academia, the site of major potential for early and career defining mentoring for women.

In general, US women physicians have been powerful advocates for research on women's health, and for promoting the inclusion and adequate representation of women in clinical research studies. How can we incorporate this valuable resource to best advantage in the cardiology community?

\section{WOMEN IN CARDIOLOGY}

In $20036 \%$ of fellows of the American College of Cardiology (ACC) were women, but women represented $14 \%$ of the affiliates-in-training. The American Board of Internal Medicine reported an increase in the percentage of first year women cardiology trainees from $13 \%$ in $1994-95$ to $18 \%$ in 2002-3. Listing of both primary and secondary roles (with obvious overlap) showed that $79 \%$ of women were clinical cardiologists, $31 \%$ echocardiographers, $18 \%$ invasive cardiologists, $13 \%$ were in research, $10 \%$ were interventional cardiologists, $9 \%$ were electrophysiologists, and 4-5\% each were nuclear cardiologists or transplant cardiologists. Women were more likely to function as clinical cardiologists, echocardiographers, transplant cardiologists, or researchers than their male peers.

Eighty one per cent of women were adult cardiologists, $17 \%$ paediatric cardiologists, and $1.8 \%$ cardiovascular surgeons. ${ }^{4}$ A total of 120 women were board certified in cardiothoracic and/or thoracic surgery, with four or five women fellows trained each year. Three quarters of these women surgeons were in private practice.

In this same survey, $71 \%$ of women $(v 90 \%$ of men) were married and $63 \%$ of women ( $v 88 \%$ of men) had children. Interruption of training or practice for more than a month had occurred in $30 \%$ and $46 \%$, respectively, of women versus $20 \%$ and $13 \%$, respectively, of men-most commonly related to pregnancy and childbirth. Fifty per cent of men with children had all childcare provided by a spouse versus $8 \%$ of women.

Forty four per cent of women compared with $17 \%$ of men had altered their training or practice to reduce occupational radiation exposure risk. Twenty three per cent of women as compared with $8 \%$ of men had selected a career track to minimise such radiation exposure.

Abbreviations: ACC, American College of Cardiology; AHA, American Heart Association; BCS, British Cardiac Society 
Mentoring during cardiology training was reported comparably by both sexes, but $14 \%$ of women as compared with $1 \%$ of men had had a woman mentor. Mentors equally exerted a positive influence on career encouragement, research participation, and role modelling for women and men, but women's mentors were more commonly described as negative personal role models.

\section{THE AMERICAN HEART ASSOCIATION: WOMEN IN CARDIOLOGY COMMITTEE}

Following informal discussions in the early 1990s and subsequent formation of a task force on women in cardiology in 1992 within the Council on Clinical Cardiology, the Women in Cardiology Committee was established in 1993. It was charged to facilitate the professional development of women cardiologists and to positively impact the number of US women physicians choosing cardiology as a career. Its mission included promotion and fostering of successful clinical and research careers in cardiology among women physicians and encouraging participation of women both in the Council on Clinical Cardiology and in other activities of the American Heart Association (AHA), increasing their visibility and leadership roles.

Liaison was established in 1995 with the newly formed task force on women in cardiology of the ACC and subsequently with its Women in Cardiology Committee.

During the past decade the Women in Cardiology Committee has sponsored an annual luncheon panel during the scientific sessions of the AHA as a forum for networking and professional development. A Women in Cardiology Travel Grant Program was initiated to foster the professional development of women fellowship trainees and to recognise their outstanding academic and clinical performance; attendance of 25 women cardiology fellowship trainees is supported at each annual scientific sessions. Grant recipients attend an awards dinner and a speaker skills workshop. The success of this undertaking is evidenced by increased numbers of women members and fellows of the Council on Clinical Cardiology, with sizeable representation of women on the Council's Executive Committee and a woman currently serving as council vice-chair.

The Women in Cardiology Mentoring Award was designed to recognise individuals who effectively mentored women cardiologists. The award recipient is recognised at the Council on Clinical Cardiology annual dinner. One of my most valued honours was being selected as the initial recipient of this Mentoring Award.

\section{THE AMERICAN COLLEGE OF CARDIOLOGY: WOMEN IN CARDIOLOGY COMMITTEE}

The Women in Cardiology Committee was organised as an Ad Hoc Committee in 1994 and became a standing committee of the ACC in 1998. It was designed to benefit the college membership as a whole, but specifically to address the professional needs and concerns of women cardiologists and to improve the quality of cardiovascular care for women. The goals of the committee were to increase the recruitment of women into cardiology and to enhance their professional development and advancement as ACC members. In addition to changing previously gender specific to gender non-specific title designations in the leadership organisation of the ACC, initiatives were promulgated to increase the number of women represented in the college's committees and task forces. There was a compelling need for increased participation of women in the governance, educational activities and advocacy roles of the ACC. An annual special session during the scientific sessions addresses the specific committee charge to represent the interests of women cardiologists in developing initiatives and programmes; to serve as a resource to the ACC on matters relating to the professional development of women cardiologists; in standards of safety for delivery and receipt of cardiovascular care; and in recommending changes in training programmes, mentoring, networking, and advisement for the advancement of interested and promising women cardiologists.

A major early activity of the Women in Cardiology Committee was the 1996 ACC Professional Life Survey ${ }^{4}$ to ascertain how career decisions of women and men cardiologists affected their professional and personal lives. The resulting statistics are presented earlier in this manuscript. Major gender based differences included more women in non-invasive and academic practices, more child and elder care responsibilities for women, more altered plans for training and practice in women to reduce radiation exposure, increased perception by women of discrimination, and less advancement and decreased satisfaction of women with their overall career choices. Related to this survey, the committee was pivotal in the development of the Radiation Safety in the Practice of Cardiology Expert Consensus document. ${ }^{5}$

During the 2001 ACC annual scientific sessions a joint meeting was hosted by this committee for women cardiologists representing other national and international cardiology societies. Participating were women cardiologists from the AHA scientific councils, the European Society of Cardiology, the Association of Black Cardiologists, the North American Society of Pacing and Electrophysiology, the American Society of Nuclear Cardiology, and the Society of Cardiac Angiography and Intervention. The committee was represented at the AMA Women Physician's Leadership Summit, the Society for Women's Health Research, WomenHeart, the National Coalition of Women with Heart Disease, as well as at conferences on women's health research sponsored by the National Institutes of Health. More recently the committee participated in the Bethesda Conference on Workforce to address "How to encourage more women to choose a career in cardiology" ${ }^{6}$

Beginning in January 2005, the ACC will create a two year pilot programme to test the viability of ACC member sections to provide a mechanism, outside of the traditional committee structure, for groups with special interests within the ACC membership to work for the advancement of their particular objectives. As such, a Women in Cardiology section will be undertaken to identify and develop initiatives to facilitate the career advancement and professional development of women cardiologists. Further initiatives will address the increased involvement of women cardiologists in ACC activities and leadership; improved networking opportunities; increased and improved mentoring opportunities; and workforce issues to encourage more women to choose careers in cardiology. The Women in Cardiology section will meet twice yearly, at the AHA and at the ACC annual scientific sessions.

\section{WOMEN IN THORACIC SURGERY}

This 65 member non-profit organisation has four goals: the mentoring of younger women; the delivery of high quality patient care; public education about heart disease in women; and the provision of continuing medical education.

\section{CHALLENGES FOR THE FUTURE}

What has been accomplished extremely well in US medicine has been the recruitment of women to medicine; currently about half of all medical students are women. What are the steps that must be taken to encourage comparable representation of women in cardiology, to create an environment for our specialty that is welcoming, multifaceted, exciting, and offers opportunities to contribute?

The measuring and benchmarking has begun, a necessity for assessing progress. We can celebrate our early 
accomplishments in the past decade in the increase in women cardiology fellowship trainees. Currently a woman is president of the AHA and a woman is president-elect of the ACC.

What is needed is clarification of the expectations of our specialty: what are the cardiology community's values in the context of patient care, of teaching and of research? What is the culture of cardiology in the context of professional/ personal life balance of responsibilities? How will our specialty advocate for such balance in both the training and the workplace environments?

Needed are increased women leaders in academia, as well as more women mentors and role models in cardiology (as well as male mentors for women). We must acknowledge image issues for the prior traditionally male domain of cardiology, including the balancing of career and personal life. The foundation of our continued success is based on acknowledging that a successful career for women in cardiology does not preclude marriage and motherhood. We must engage in conversations articulating the diversity of needs of women (as well as men) cardiologists that must be met without relinquishing current gains. Negotiation does not imply weakness and is requisite for such options as creative training and career choices and job sharing. Finally, we must showcase the exciting spectrum of clinical and research opportunities available to women in cardiology.

\section{REFERENCES}

1 Timmis AD, Baker C, Banerjee $S$, et al. Women in UK cardiology: report of a Working Group of the British Cardiac Society. Heart 2005:91:283-9.

2 Graduate Medical Education. Appendix II. JAMA 2002;288:1151-64.

3 Association of American Medical Colleges. http://www.aamc.org

4 Limacher MC, Zaher CA, Walsh MN, et al. The ACC professional life survey: career decisions of women and men in cardiology. A report of the committee on women in cardiology. J Am Coll Cardiol 1998;32:827-35

5 Limacher MC, Douglas PS, Germano G, et al. Radiation safety in the practice of cardiology. ACC expert consensus document. J Am Coll Cardiol 1998:31:892-913.

6 Warnes CA, Fedson SE, Foster E, et al. Bethesda conference on workforce. Working group 2: How to encourage more women to choose a career in cardiology. J Am Coll Cardiol 2004;44:238-41.

\title{
IMAGES IN CARDIOLOGY
}

\section{Massive pulmonary embolism in a patient with Streptococcus agalactiae tricuspid valve endocarditis}

\begin{abstract}
19 year old, previously healthy, woman was admitted with complaints woman was admitted with complaints of septic shock. There was no history of alcohol or intravenous drug abuse. A chest computed tomographic scan visualised two areas of infarction in the right lung. These findings prompted an echocardiographic examination, which demonstrated a large $(6 \times 3 \mathrm{~cm})$, lobulated, mobile mass, partially obstructing the tricuspid valve, and prolapsing into the right ventricle. (panel A, arrow).

The diagnosis of tricuspid valve endocarditis was confirmed when Streptococcus agalactiae grew in three out of four admission peripheral blood samples. Because of disseminated intravascular coagulation with persistent, severe, thrombocytopenia $\left(<10000\right.$ platelets $\left./ \mathrm{mm}^{3}\right)$, urgent tricuspid valve surgery was not possible. On the third hospital day, the patient showed signs of decreased oxygenation, requiring ventilatory support, and followed by cardiopulmonary arrest. Despite all resuscitative efforts, including initiation of cardiopulmonary bypass, the patient died.

A post-mortem examination revealed complete obstruction of the right pulmonary artery by a $3 \times 2 \mathrm{~cm}$ mass, representing a fragment of bacterial vegetation (panel $\mathrm{C}$ ). The tricuspid valve was eroded with an associated myocardial abscess (panel B, arrowheads). On microscopic examination, the tricuspid valve surface was coated with numerous Gram-positive cocci.

$S$ agalactiae is an uncommon cause of native tricuspid valve endocarditis in the
\end{abstract}

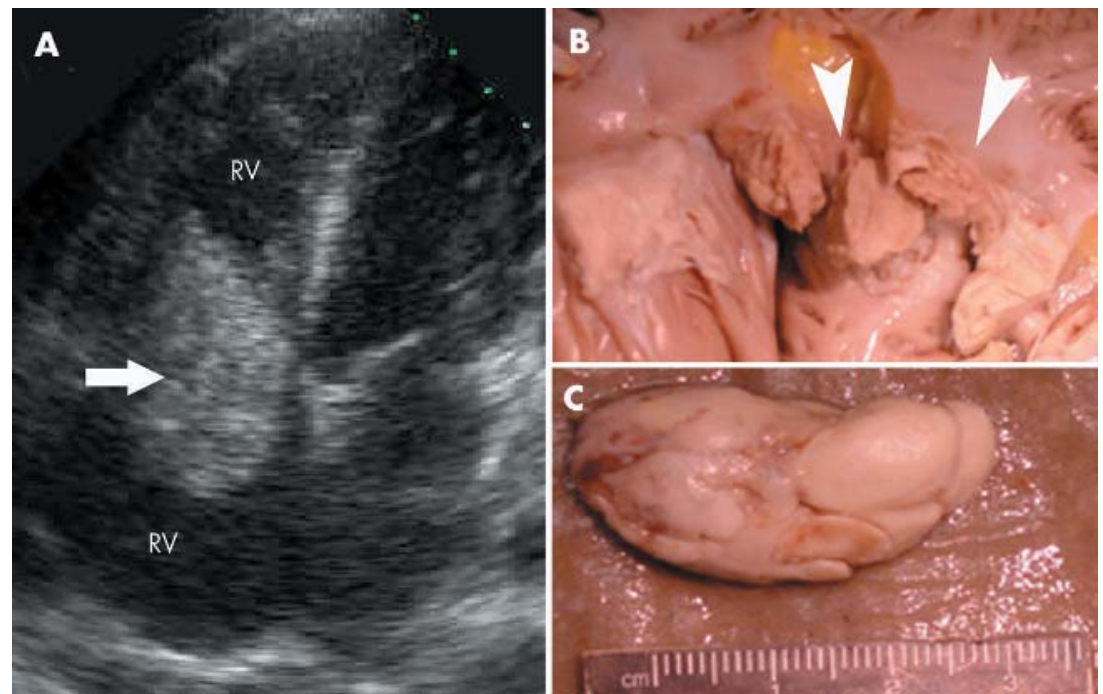

(A) Apical four chamber view with large vegetation of the tricuspid valve (arrow). (B) Tricuspid valve, which is eroded, with an associated myocardial abscess (arrowheads). (C) Embolus (bacterial vegetation) recovered from the right pulmonary artery.

absence of predisposing conditions such as intravenous drug abuse, diabetes mellitus, alcoholism, or pregnancy. The bacteria lack fibrinolysin production, which might explain the unusual large, friable vegetations, and the high rate of embolisation. 